\title{
Postnatal increase in insulin-sensitive glucose transporter expression is associated with improved recovery of postischemic myocardial function
}

Ingeborg Friehs, $\mathrm{MD}^{\mathrm{a}}$

Hung Cao-Danh, $\mathrm{PhD}^{\mathrm{a}}$

Christof Stamm, MD ${ }^{a}$

Douglas B. Cowan, $\mathrm{PhD}^{\mathrm{b}}$

Francis X. McGowan, MD ${ }^{\mathrm{b}}$

Pedro J. del Nido, MDa

From the Departments of Cardiac Surgery ${ }^{a}$ and Anesthesiology/Critical Care, ${ }^{\text {b Chil- }}$ dren's Hospital, Harvard Medical School, Boston, Mass.

This work was supported in part by grants from the National Institutes of Health, HL 63095 (P.J.d.N.), and HL 52589 (F.X.M.).

Received for publication July 19, 2002; revisions requested Sept 5, 2002; revisions received Sept 25, 2002; accepted for publication Oct 3, 2002.

Address for reprints: Pedro J. del Nido, MD, Department of Cardiac Surgery, Children's Hospital, Harvard Medical School, 300 Longwood Avenue, Boston, MA 02115 (E-mail: pedro.delnido@tch.harvard.edu).

J Thorac Cardiovasc Surg 2003;126:263-71

Copyright (C) 2003 by The American Association for Thoracic Surgery

0022-5223/2003\$30.00+0

doi:10.1016/S0022-5223(03)00034-5
Objective: Glucose is an important substrate for energy production in the developing heart. Increased glucose uptake rate and metabolism during ischemia and reperfusion are closely linked to postischemic myocardial recovery. The initial rate-limiting step for glycolysis is the transport of glucose across the plasma membrane by glucose transporters (GLUT-1 and GLUT-4). We hypothesized that changes in GLUT-1 and GLUT-4 expression in developing hearts lead to age-dependent adaptive changes in glucose uptake capacity and influence tolerance to ischemia.

Methods: Western-immunoblotting was performed to determine GLUT-1 and GLUT-4 expression in myocardial tissue from 1, 2, and 3-week-old and adult rabbits. Glucose uptake rate was measured with ${ }^{31} \mathrm{P}$-nuclear magnetic resonance spectroscopy using 2-deoxyglucose as substrate in isolated perfused hearts. Hearts from same age rabbits were perfused in the Langendorff mode with crystalloid buffer or buffer plus a GLUT-4 specific antibody in order to determine GLUT-4 mediated effects on myocardial protection. The hearts were subjected to 30 minutes of normothermic ischemia followed by reperfusion. Cardiac contractile function measurements were obtained pre- and postischemia. Tissue lactate accumulation was measured in all groups at end-ischemia

Conclusions: Insulin-regulated glucose transporter (GLUT-4) expression in the heart increased gradually after birth reaching nearly adult levels by 3 weeks of age. Corresponding with the higher amount of GLUT-4 protein, improved recovery of postischemic contractile function was seen in older hearts in association with increased anaerobic glycolytic capacity. Interventions to accelerate postnatal GLUT-4 expression may improve ischemic tolerance in the neonatal heart.

I schemia induces multiple changes in myocardial cell metabolism including a marked increase in glucose uptake and utilization. ${ }^{1-3}$ During ischemia, and particularly during early reperfusion, there is a shift in myocardial substrate utilization from free fatty acid oxidation to dependence on glycolysis for energy production. ${ }^{4}$ It has been shown experimentally that increased glucose uptake and glycolysis during ischemia and early reperfusion are associated with improved postischemic myocardial recovery. ${ }^{3,5,6}$ Developmentally, age-dependent differences in the vulnerability of myocardium to ischemic injury have been suggested. ${ }^{7-9}$ Clinical reports suggest that in the early neonatal period, the heart is more vulnerable to injury from global ischemia than the mature myocardium. ${ }^{10-12}$ Lower levels of high-energy phosphates have been detected in infants compared to adults undergoing cardiac surgery. ${ }^{12}$ Experimentally, in various species, the onset of ischemic contracture due to formation of rigor 
complexes and depletion of high-energy phosphates has been shown to occur earlier in neonatal hearts compared to adults. ${ }^{8,13,14}$ Paradoxically, greater anaerobic glycolytic capacity and higher glycogen reserves have been demonstrated in the neonatal hearts and potentially this may provide an advantage over adult hearts with respect to tolerance to ischemic injury. $3,15,16$

Under physiologic conditions, the myocardium of neonatal animals has a high capacity to utilize glucose, while adult myocardium utilizes primarily fatty acids as its energy source. Forty-eight percent of adenosine triphosphate (ATP) production in the myocardium of a neonatal rabbit is derived from glycolysis as compared to $20 \%$ in the adult. ${ }^{17}$ There are also significant differences in the levels of circulating substrates during cardiac development and maturation. ${ }^{18,19}$ Whether the transition in substrate utilization from neonatal to adult myocardium depends on changes in substrate availability or in intracellular substrate utilization remains to be determined. There is evidence that adaptive changes in intracellular metabolic signals that coordinate carbohydrate and fatty acid utilization in the myocardium occur during development. ${ }^{20,21}$

The transport of glucose across the plasma membrane is the initial step in myocardial glucose metabolism, and the number of facilitative glucose transport proteins present in the sarcolemma determines the rate of glucose uptake. Two glucose transporters are expressed in cardiomyocytes, the ubiquitous GLUT-1 and the insulin-regulated transporter GLUT-4. It has been shown that GLUT-1 and GLUT-4 have different affinity for glucose and transport capacity, and that GLUT-4 is the transporter most responsible for glucose uptake in mature myocardium. These findings suggest that the two glucose transporters expressed in the heart play different roles under physiologic and nonphysiologic conditions. ${ }^{22}$ For example, it has been shown that ischemia causes substantial translocation of the insulin-responsive glucose transporter (GLUT-4) to the plasma membrane resulting in greater glucose transport capacity. ${ }^{23}$

The present study was undertaken to determine the coordinate expression of GLUT-1 and GLUT-4 in the developing rabbit heart. We tested the hypothesis that developmentally regulated differences in glucose transporter expression affect glucose uptake rate and correlate with susceptibility to ischemia/reperfusion injury during maturation. To determine this relationship, we measured glucose transporter protein content, and insulin-stimulated glucose transport rate. Tissue lactate production during the ischemic period was measured as an indicator of anaerobic glycolytic activity.

\section{Materials and Methods}

\section{Myocardial GLUT-1 and GLUT-4 Content by} Western-Immunoblotting

New Zealand White rabbits of either sex at different time points in their development (1-day, 1-, 2-, 3-, 4-week-old, and adult) were studied. Following intravenous or intraperitoneal administration of a mixture of heparin $(500 \mathrm{U} / \mathrm{kg})$, ketamine $(50 \mathrm{mg} / \mathrm{kg})$, and xylazine $(2.5 \mathrm{mg} / \mathrm{kg})$, the hearts were rapidly removed flushed with cold Krebs-Henseleit (KH) buffer solution and the left ventricles (LV) were frozen in liquid nitrogen. LV tissue was further processed as previously described and $25 \mu \mathrm{g}$ protein from the crude supernatant fraction was then used for gel electrophoresis with $10 \%$ sodium dodecyl sulfate (SDS) polyacrylamide gel electrophoresis gels. ${ }^{24,25}$ After transfer to nitrocellulose membranes, the membranes were incubated in 5\% nonfat dry milk in TBST (10 $\mathrm{mmol} / \mathrm{L}$ Tris- $\mathrm{HCl} \mathrm{pH} \mathrm{7.5,} 100 \mathrm{mmol} / \mathrm{L} \mathrm{NaCl}, 0.1 \%$ Tween 20 ) to block unspecific binding sites and then with primary antibodies to either GLUT-1 (East Crest, Mass) or GLUT-4 (R\&D Systems Inc., Minneapolis, Minn) at a dilution of 1:1000 followed by incubation with horseradish peroxidase-conjugated secondary antibody (Jackson Immuno Research Labs, Inc., West Grove, Penn) at a dilution of 1:10000. The bound antibody was detected by the enhanced chemoluminescence method according to the manufacturer's instruction (Amersham Life Science, Arlington Heights, Ill). After exposure on films, quantitative protein analysis was performed by laser densitometry.

\section{2-Deoxyglucose Uptake}

Glucose uptake was determined by ${ }^{31} \mathrm{P}$-nuclear-magnetic-resonance (NMR) spectroscopy using 2-deoxyglucose (2-DG) as substrate. We have previously described and validated this method in detail. ${ }^{24}$ Nonischemic hearts from 1-week-old (age range, 3-5 days), 2-week-old (age range, 14-15 days), 3-week-old (age range, 20-21 days), and adult rabbits (age range, 6 weeks to 6 months) were positioned within a $20-\mathrm{mm}$ solenoid radiofrequency coil. NMR spectra were acquired in an 8.45-Tesla vertical bore Bruker spectrometer (Bruker Instruments, Billerica, Mass) operating at a proton frequency of $360 \mathrm{MHz}$ and ${ }^{31} \mathrm{P}$ frequency of $145 \mathrm{using}$ ketamine $(50 \mathrm{mg} / \mathrm{kg})$ and xylazine $(2.5 \mathrm{mg} / \mathrm{kg})$ for euthanasia with the addition of heparin $(500 \mathrm{U} / \mathrm{kg})$. The hearts were rapidly excised and perfused with oxygenated $\mathrm{KH}$ solution containing glucose (10 $\mathrm{mmol} / \mathrm{L}$ ) but no insulin. After a 30-minute stabilization period, the perfusate was switched to a modified $\mathrm{KH}$ solution containing bovine insulin $(10 \mathrm{IU} / \mathrm{L})$, a reduced glucose content $(1 \mathrm{mmol} / \mathrm{L})$ and a concentration of $3 \mathrm{mmol} / \mathrm{L}$ 2-DG (Sigma, Chemical Company, St. Louis, Mo). The rate of 2-DG accumulation (proportional to the rate of glucose uptake) was quantified by a second order polynomial function.

\section{Isolated Heart Preparation and Cardiac Function Measurements}

One-, 2-, 3-week-old, and adult rabbits were studied. Following intravenous or intraperitoneal administration of heparin (500 $\mathrm{U} / \mathrm{kg})$, ketamine $(50 \mathrm{mg} / \mathrm{kg})$, and xylazine $(2.5 \mathrm{mg} / \mathrm{kg})$ the hearts were rapidly excised. After aortic cannulation the hearts were perfused in the nonworking, nonrecirculating Langendorff mode at constant flow perfusion with oxygenated $\mathrm{KH}$ solution $\left(37^{\circ} \mathrm{C}, \mathrm{pH}\right.$ 7.4, containing: $11 \mathrm{mmol} / \mathrm{L}$ glucose, $10 \mathrm{IU} / \mathrm{L}$ insulin). In separate sets of experiments, GLUT-4 antibody (R\&D Systems Inc.) in a concentration of $0.2 \mu \mathrm{g} / \mathrm{mL}$ was added to the perfusate. The concentration was chosen based on previous experiments that proved a significant impairment of postischemic recovery could be achieved without influencing preischemic contractility. Perfusion 

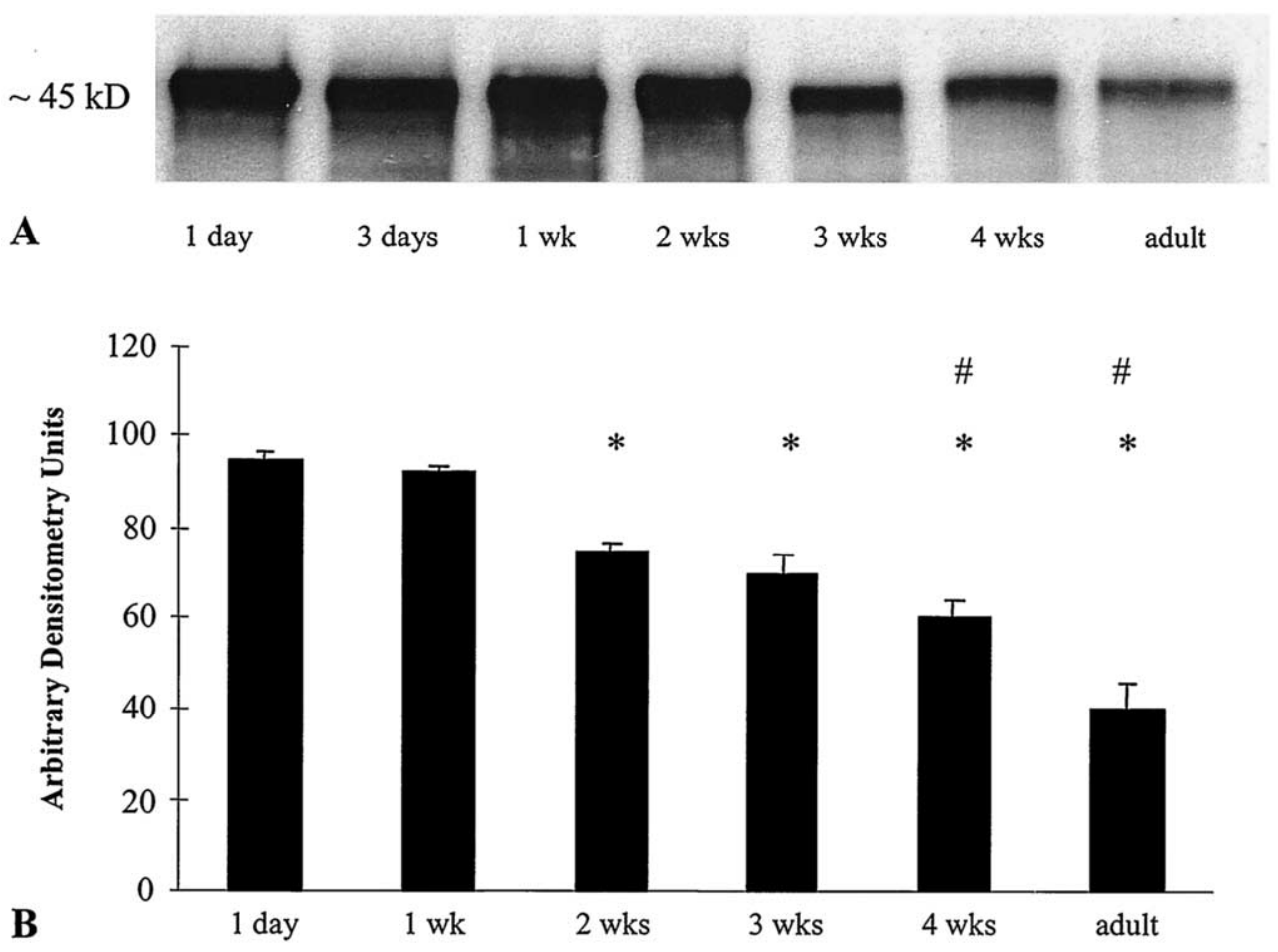

Figure 1. A, Representative Western-immunoblot of GLUT-1 glucose transporter from LV myocardium of rabbits at different ages. B, Quantitation of GLUT-1 levels on immunoblots was performed by laser densitometry and is summarized in this bar graph. Results are expressed in arbitrary densitometry units (n=6/group; ${ }^{*} \leq .05$ vs 1 day and 1 week; $\# P \leq .05$ vs 2 weeks).

rate was normalized for the absolute weight of the heart and thereby maintained equal for all hearts $\left(10 \mathrm{~mL} \cdot \mathrm{min}^{-1} \cdot \mathrm{g}^{-1}\right.$ heart weight). Constant flow rate was maintained with a roller pump (Master Flex; Cole Parmer, Chicago, Ill).

LV pressure measurements were obtained with a latex balloon inserted into the LV cavity and connected to a catheter tip pressure transducer (Millar Instruments Co, Houston, Tex). Heart rate and LV developed pressure (calculated from LV systolic pressure minus diastolic pressure) at balloon volumes adjusted to produce a diastolic pressure in the range of 5 to $10 \mathrm{~mm} \mathrm{Hg}$, were determined after a 30-minute stabilization period as baseline measurements. After induction of ischemia, the intracavitary balloon was emptied and remained empty during the entire ischemic period and during reperfusion to simulate the beating, nonworking heart. Hearts were maintained at $36.5^{\circ} \mathrm{C} \pm 0.5^{\circ} \mathrm{C}$ for 30 minutes and reperfused for 30 minutes. At the end of reperfusion, the balloon was inflated to its preischemic volume and intracavitary pressure data were recorded and compared with baseline data. Hearts were weighed prior to and after a 48-hour drying period to calculate wet weight/ dry weight ratios.

\section{Lactate Measurements}

At end-ischemia coronary effluent of first minute reperfusion was collected and a sample of the LV myocardium was snap frozen in liquid nitrogen. The frozen tissue was further processed with $6 \%$ hydrochloric acid and lactate content of effluent and LV myocar- dial sample were determined by a colorimetric kit (Sigma Chemical Company).

\section{Statistical Analysis}

Data are expressed as the mean \pm SEM and analyzed using SPSS software (version 9.0; SPSS Inc, Chicago, Ill). Comparisons between groups were made with one-way analysis of variance. $P$ values were corrected by Bonferroni's post hoc correction. If normal distribution and equal variance testing was passed, a standard $t$ test was used.

\section{Animal Care}

All animals received humane care in compliance with the Principles of Laboratory Animal Care formulated by the National Society for Medical Research and the Guide for the Care and Use of Laboratory Animals prepared by the National Academy of Sciences and published by the National Institutes of Health (NIH Publication No. 86-23, revised 1996). The protocol was reviewed and approved by the Animal Care Committee at Children's Hospital Boston.

\section{Results}

Myocardial GLUT-1 and GLUT-4 Content

GLUT-1 and GLUT-4 protein content in LV myocardium from rabbits of different ages is shown in Figures 1 and 2. 

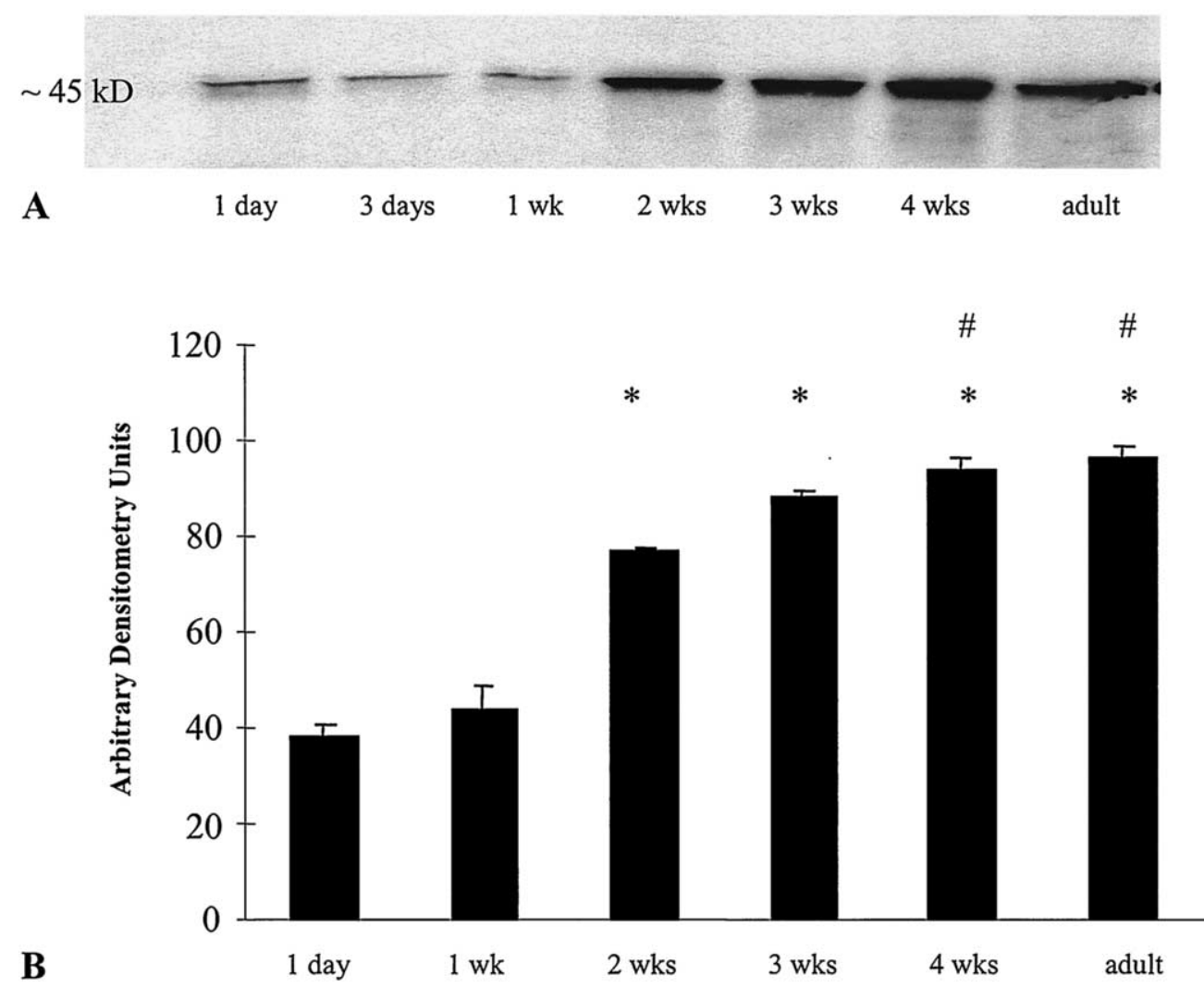

Figure 2. A, Representative Western-immunoblot of GLUT-4. Glucose transporter from LV myocardium of rabbits at different ages. B, Quantitation of GLUT-4 levels on immunoblots was performed by laser densitometry and is summarized in this bar graph. Results are expressed in arbitrary densitometry units ( $n=6 /$ group; ${ }^{*} \leq .05$ vs 1 day and 1 week; $\# P \leq .05$ vs 2 weeks).

There was a decline in GLUT-1 protein content with maturation. GLUT-1 protein levels were lower starting at 2 weeks after birth compared to 1 day and 1 week old rabbits ( $P \leq .05$ vs 1 day and 1 week). Coincident with the decline in GLUT-1 protein levels, there was an increase in GLUT-4 protein content, reaching almost adult levels by 3 weeks. The switch from predominantly GLUT-1 to GLUT-4 expression occurred at about 2 weeks.

\section{2-DG Uptake}

Figure 3 shows the rate of insulin-stimulated 2-deoxyglucose-6-phosphate (2-DG-6-P) accumulation over a period of 30 minutes in isolated rabbit hearts at different time points in their development ( 1 week, 2 weeks, 3 weeks, adult). Glucose uptake as indicated by 2-DG-6-P accumulation was lower in 1-week-old hearts compared to all other age groups with a slower rate of rise and lower total accumulation after 30 minutes of perfusion with 2-DG $(P \leq .05)$. By 3 weeks, insulin-stimulated 2-DG-6-P accumulation had already reached almost adult levels.

\section{Contractile Function}

Preischemic contractile function measurements recorded after a 30-minute stabilization period are summarized in Table 1. Hearts from 1-week-old rabbits had lower left ventricular developed pressure (calculated from systolic minus diastolic pressure) preischemia compared to all other age groups ( $P$ $\leq .05)$.

After 30 minutes of normothermic ischemia, and 30 minutes of reperfusion, in all four age groups, diastolic pressure increased compared to preischemic baseline values $(P \leq .05$; data not shown $)$ and there was no difference between the age groups. There was no difference in dry weight to wet weight ratios pre- or postischemia between the groups (data not shown).

Postischemic developed pressure was lower in 1-weekold hearts compared to baseline measurements $(73 \pm 6 \mathrm{~mm}$ $\mathrm{Hg}$ preischemia vs $44 \pm 2 \mathrm{~mm} \mathrm{Hg}$ postischemia; $P \leq .05$ ). Two-week-old and adult hearts had better recovery of developed pressure postischemia $(92 \pm 1 \mathrm{~mm} \mathrm{Hg}$ vs $73 \pm 4$ $\mathrm{mm} \mathrm{Hg}$, pre- vs postischemia; and $92 \pm 2 \mathrm{~mm} \mathrm{Hg}$ vs $77 \pm$ $4 \mathrm{~mm} \mathrm{Hg}$ pre- vs postischemia, respectively) compared to 


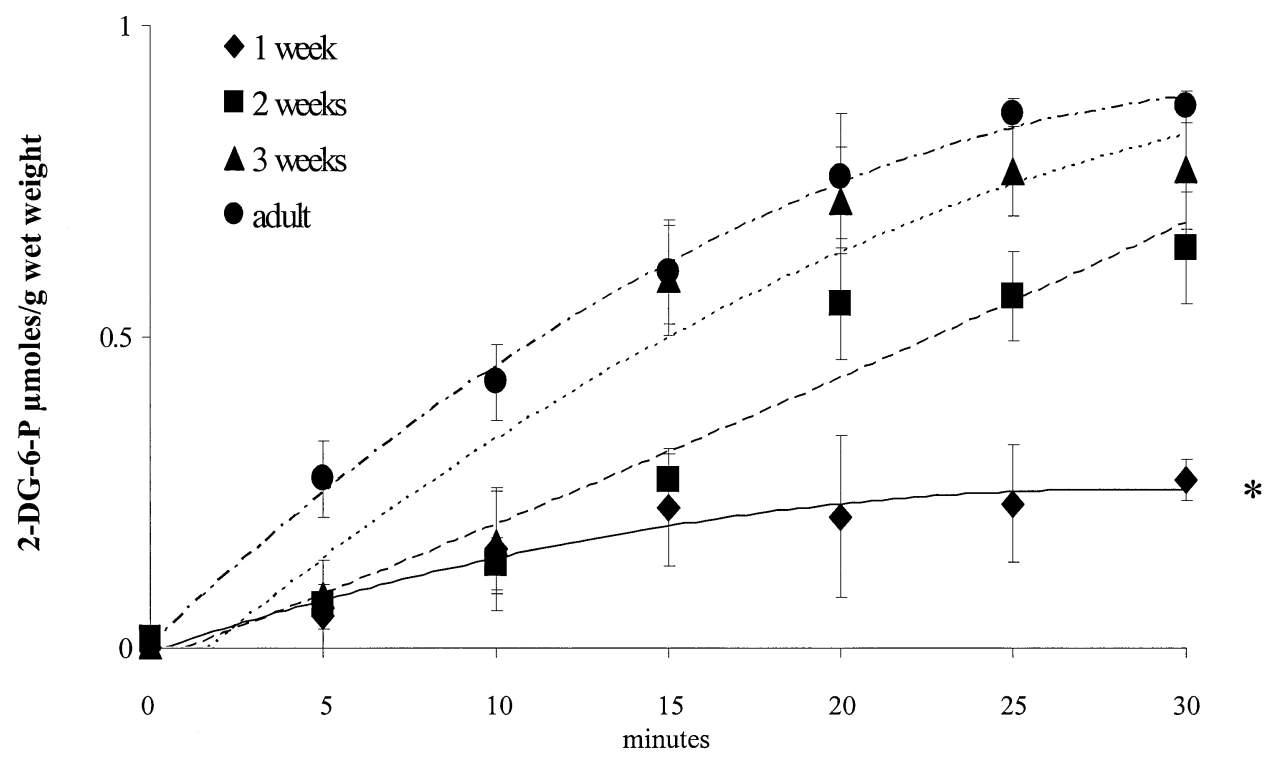

Figure 3. 2-Deoxyglucose uptake rate and phosphorylation was measured as accumulation of 2-deoxyglucose-6phosphate by ${ }^{31} \mathrm{P}-\mathrm{NMR}$ spectroscopy over a period of 30 minutes in hearts at different ages (1 week, 2 weeks, 3 weeks, adult). $n=6 /$ group, ${ }^{*} P \leq .05$ vs 2 weeks, 3 weeks, and adult.

1-week-old $(P \leq .05)$. In hearts from 3 -week-old rabbits developed pressure recovered to preischemic levels ( $92 \pm 2$ $\mathrm{mm} \mathrm{Hg}$ vs $81 \pm 3 \mathrm{~mm} \mathrm{Hg}$, pre- vs postischemia). Developed pressure during reperfusion, expressed as percent recovery from preischemic values is depicted in Figure 4, A. One-week-old hearts had the poorest recovery $(62 \% \pm 5 \%)$ of all age groups $(P \leq .05)$. The addition of GLUT-4 antibody to the perfusate did not affect postischemic function in 1-week-old hearts, however, GLUT-4 antibody significantly impaired postischemic functional recovery of adult hearts $(P<.05$; Figure $4, B)$.

\section{Myocardial Tissue Lactate Levels at End-Ischemia}

Tissue lactate levels at end-ischemia are depicted in Figure $5, A$. The highest levels of lactate were found in the adult LV myocardium. Blocking GLUT-4 transporters with GLUT-4 antibodies in the perfusate had no effect on tissue lactate accumulation during ischemia in 1-week-old hearts but significantly decreased tissue lactate levels in adult hearts $(P \leq .05$; Figure $5, B)$.

\section{Discussion}

In this study we have demonstrated that GLUT-1 is the predominant glucose transporter expressed in neonatal rabbit myocardium. By 2 weeks of age, GLUT-4 expression reached adult levels and GLUT-1 expression declined progressively to adult levels as well. With maturation, glucose uptake increased and paralleled the rise in GLUT-4 expression. Increased GLUT-4 content in myocardium correlated
TABLE 1. Baseline cardiac function measurements

\begin{tabular}{lcccc}
\hline & 1 week & 2 weeks & 3 weeks & Adult \\
\hline HR & $201 \pm 5^{*}$ & $197 \pm 5^{*}$ & $200 \pm 4^{*}$ & $148 \pm 7$ \\
DP & $6 \pm 0.5$ & $7 \pm 0.8$ & $6 \pm 0.7$ & $7 \pm 0.2$ \\
DevP & $73 \pm 6^{*}$ & $92 \pm 1$ & $92 \pm 2$ & $92 \pm 2$
\end{tabular}

$H R$, Heart rate; $D P$, diastolic pressure; DevP, developed pressure (systolicdiastolic pressure).

Values are expressed as mean \pm SEM ( $n=6 /$ group).

${ }^{*} P \leq .05$; vs adult.

closely with increased anaerobic glycolytic capacity and improved tolerance to ischemia.

In mammalian cells, glucose is not freely permeable across the plasma membrane but must enter by facilitated diffusion. Glucose transporter proteins that facilitate the movement of glucose across the plasma membrane in an energy independent manner are responsible for this process. The various members of the glucose transporter family have distinct structure, function, and tissue distribution. ${ }^{22,26-28} \mathrm{In}$ the adult heart, GLUT-1 is present in low levels and is responsible for "basal" glucose uptake. ${ }^{29}$ GLUT-4, the insulin-regulated transporter, is expressed in cells that can rapidly increase glucose transport across the plasma membrane, such as skeletal, and cardiac myocytes, and adipocytes. ${ }^{30}$ In cardiac myocytes, in the basal state, GLUT-1 is evenly distributed between the plasma membrane and lowdensity microsomal pools whereas GLUT-4 is almost entirely stored in an intracellular pool. ${ }^{31,32}$ Insulin interaction with its membrane receptor results in rapid translocation of 

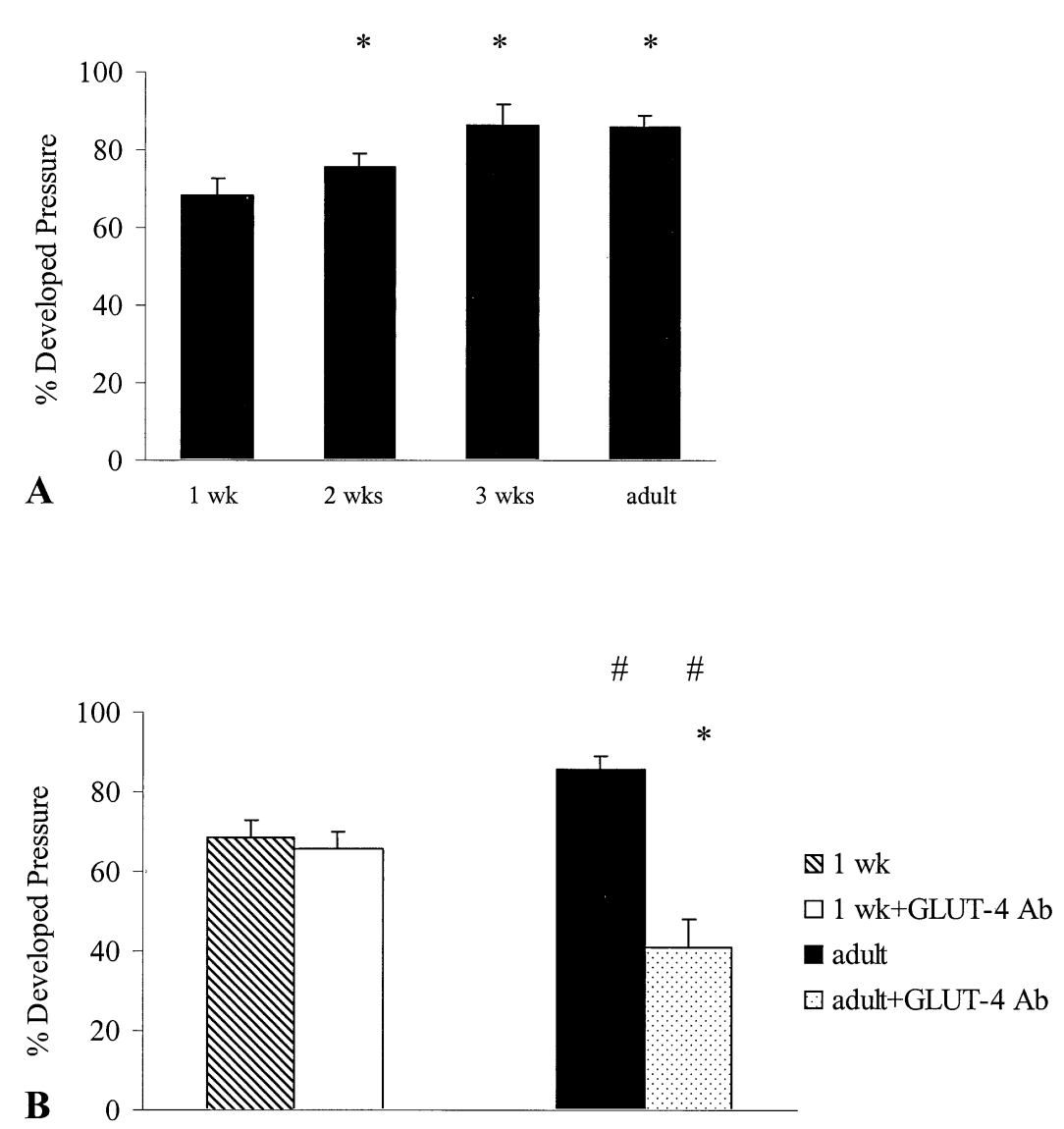

Figure 4. A, Postischemic developed pressure expressed as percent of preischemic measurements of 1 week, 2 weeks, 3 weeks, and adult hearts. ( $n=6 /$ group, ${ }^{*} P \leq .05$; vs 1 week). B, Postischemic developed pressure expressed as percent of preischemic measurements in 1-week-old and adult hearts with and without GLUT-4 antibody present in the perfusate. ( ${ }^{*} \leq .05$ vs adult; $\# P \leq .05$ vs 1 week \pm GLUT-4 antibody).

GLUT-4 containing intracellular vesicles to the cell membrane. After cessation of stimulation, GLUT-4 is resequestered into the intracellular vesicles. ${ }^{33}$

GLUT-1 is the predominant isoform in muscle and adipocytes perinatally. ${ }^{34}$ This high expression of GLUT-1 is common in not only insulin-responsive tissues like the heart, skeletal muscle, or adipocytes but has also been shown in rat and rabbit brain, lung, liver, and kidney. ${ }^{35,36} \mathrm{In}$ all these tissues GLUT-1 levels rapidly diminish after birth. In skeletal muscle, GLUT-1 regression occurs concomitantly with an increase in GLUT-4 expression. ${ }^{34}$ Our results are consistent with these findings and indicate that during early neonatal life, GLUT-1 is the predominantly expressed isoform in myocardium. During the fetal and early neonatal period, tissues such as heart and diaphragm have a high rate of glucose uptake and utilization, greater than that seen in mature tissues. ${ }^{37}$

The factors that trigger GLUT-4 induction and GLUT-1 regression during perinatal development are unknown. Previously published data suggest that thyroid hormone may play a role in the regulation of muscle glucose transporters during development. GLUT-1 and GLUT-4 gene expression is highly sensitive to thyroid hormone manipulation during perinatal life. ${ }^{38} \mathrm{~T}_{3}$ and $\mathrm{T}_{4}$ levels increase progressively early after birth and reach a plateau by 2 weeks of age. ${ }^{39}$ In rat heart and skeletal muscle, hypothyroidism induced at birth leads to alterations in glucose transporter expression with GLUT-4 expression being blocked and GLUT-1 carriers being augmented and concomitantly, glucose uptake in response to insulin is impaired. ${ }^{38,40}$

Several studies have demonstrated that the uptake of glucose by the mature heart is regulated by insulin via GLUT-4 activation and by enhancing incorporation of glucose transporter into the sarcolemma. ${ }^{22,30}$ In order to determine the contribution of GLUT-1 vs GLUT-4 on glucose uptake, in our studies GLUT-4 transporters were blocked by addition of a GLUT-4 specific antibody to the perfusate. In 1-week-old rabbit hearts, intervention at the level of GLUT-4 did not influence the postischemic outcome. However, in adult hearts impairing GLUT-4 mediated glucose 

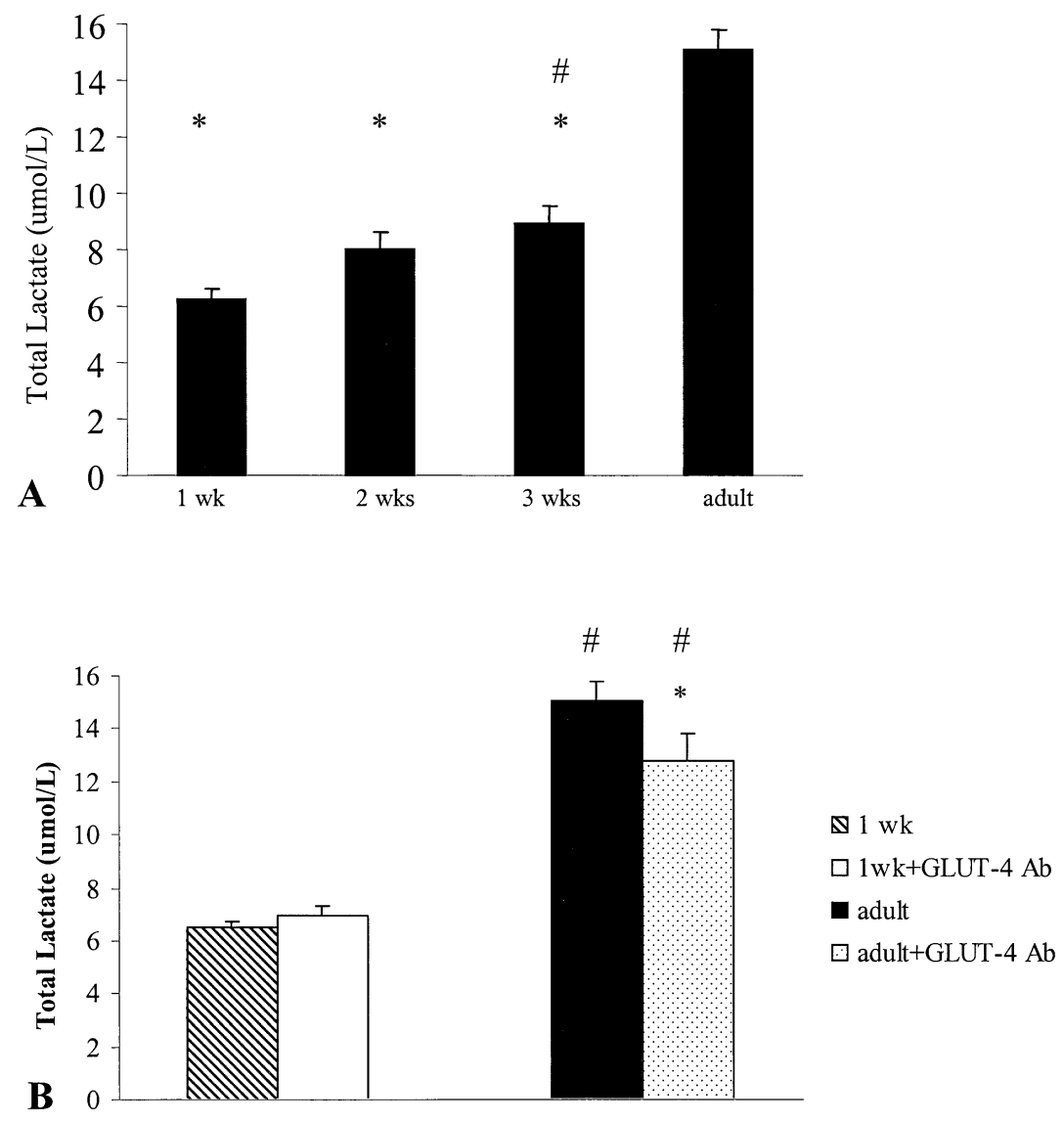

Figure 5. A, Lactate levels measured at end-ischemia are depicted in this bar graph ${ }^{*} \boldsymbol{P} \leq .05$ vs adult; \#P$\leq .05$ vs 1 week). B, Lactate levels measured at end-ischemia in 1-week-old and adult hearts with and without GLUT-4 antibody present in the perfusate (*P $\leq .05$ vs adult; $\# P \leq .05$ vs 1 week \pm GLUT-4 antibody).

uptake resulted in impaired postischemic myocardial recovery concomitant with a decrease in anaerobic glycolytic capacity. Enhanced glucose uptake during ischemia and early reperfusion has been directly linked to postischemic myocyte viability. ${ }^{6}$ Ischemia has been shown to induce a marked increase in glucose uptake presumably to increase substrate availability for glycolysis. ${ }^{6,15,41,42}$ The transition from aerobic to anaerobic glycolysis leads to a 20 -fold increase in glycolytic flux. ${ }^{43}$ This increase in glucose uptake rate is achieved by translocation of glucose transporter containing intracellular vesicles to the sarcolemma, similar to the effects of insulin. ${ }^{31,44}$ GLUT-1 is also activated during ischemia but the increase in GLUT-1 translocation is significantly lower than for GLUT- $4 .{ }^{45}$

\section{Limitations of This Study}

The use of 2-DG to estimate glucose uptake into the cell is done with ${ }^{31} \mathrm{P}-\mathrm{NMR}$ spectroscopy measuring 2-deoxyglucose-6-phosphate accumulation. This measure assumes that the affinity of the transporter and hexokinase are similar for 2-DG as they are for glucose, under the specific experimen- tal conditions. In previous studies with rabbit hearts exposed to the same experimental conditions, we have shown that hexokinase activity remains constant during the 2-DG infusion and that the 2-DG uptake rate is the same as that for radiolabeled glucose. ${ }^{24}$ To account for the different perfusion requirements of the various age hearts, perfusion rate was matched to heart weight $\left(10 \mathrm{~mL} \cdot \mathrm{min}^{-1} \cdot \mathrm{g}^{-1}\right.$ heart weight). Thus, availability of substrate and 2-DG was maintained the same for the different experimental groups. Furthermore, because handling of small hearts is more challenging, baseline ATP levels were determined in all hearts in order to detect differences due to tissue perfusion, and none were found (data not shown).

Our data support the conclusion that a switch in glucose transporter isoform expression in the postnatal heart, from GLUT-1 to GLUT-4, leads to an increase in glucose uptake rate and improved tolerance to ischemia. Upregulation of the insulin-sensitive glucose transporter GLUT-4 reaches adult levels by 3 weeks of age in the rabbit. Corresponding with the higher amount of GLUT-4 protein, insulin-stimulated myocardial glucose transport rate also reaches adult 
levels during this time period. These results indicate that low GLUT-4 expression after birth restricts the amount of exogenous glucose available to the immature heart resulting in greater vulnerability to an ischemic insult and may be an important therapeutic target.

\section{References}

1. Eberli FR, Weinberg EO, Grice WN, Horowitz GL, Apstein CS. Protective effect of increased glyoclytic substrate against systolic and diastolic dysfunction and increased coronary resistance from prolonged global underperfusion and reperfusion in isolated rabbit hearts perfused with erythrocyte suspensions. Circ Res. 1991;68: 466-81.

2. Opie LH, Camici PG. Myocardial blood flow, deoxyglucose uptake and myocyte viability in ischemia. J Nucl Med. 1992;33:1353-6.

3. Owen P, Dennis S, Opie LH. Glucose flux rate regulates onset of ischemic contracture in globally underperfused rat heart. Circ Res. 1990;66:344-54.

4. Kingsley PB, Sakon EY, Yang MQ, Zimmer SD, Ugurbil R, Folker JE. Ischemic contracture begins when anaerobic glycolysis stops: a 31P-NMR study of isolated rat hearts. Am J Physiol. 1991;261:H46978.

5. Mallet RT, Hartman DA, Bunger R. Glucose requirement for postischemic recovery of perfused working heart. Eur J Biochem. 1990; 188:481-93.

6. Opie LH. Hypothesis: glycolytic rates control cell viability in ischemia. J Appl Cardiol. 1988;3:407-14.

7. Otani H, Engelman RM, Rousou JA, Breyer RH, Lemeshow S, Das DK. The mechanism of myocardial reperfusion injury in neonates. Circulation. 1987;76(5 Pt 2):V161-7.

8. Quantz M, Tchervenkov C, Chiu RC. Unique responses of immature hearts to ischemia. Functional recovery versus initiation of contracture. J Thorac Cardiovasc Surg. 1992;103:927-35.

9. Velvis H, Hines MH, Klopfenstein HS, Berry DD, Vinten-Johansen J. Depression of cardiac function after deep hypothermic circulatory arrest in deeply anesthetized neonatal lambs. J Thorac Cardiovasc Surg. 1996;111:359-66.

10. del Nido PJ, Mickle DA, Wilson GJ, Benson LN, Weisel RD, Coles $\mathrm{JG}$, et al. Inadequate myocardial protection with cold cardioplegic arrest during repair of tetralogy of Fallot. J Thorac Cardiovasc Surg. 1988;95:223-9.

11. Kirklin J, Blackstone E, Kirklin J, McKay R, Pacifico A, Bargeron L. Intracardiac surgery in infants under age 3 months: incremental risk factors for hospital mortality. Am J Cardiol. 1981;48:500-12.

12. Bull C, Cooper J, Stark J. Cardioplegic protection of the child's heart. J Thorac Cardovasc Surg. 1984;88:287-293.

13. Hearse DJ, Garlick PB, Humphrey SM. Ischemic contracture of the myocardium: Mechanisms and prevention. Am J Cardiol. 1977;39: 986-93.

14. Sink JD, Currie WD, Pellom GL, Hill RC, Chitwood R, Wechsler AS. Correlation of mitochondrial function and ischemic contracture. J Thorac Cardiovasc Surg. 1980;79:570-8.

15. Jeremy RW, Ambrosia G, Pike MM, Jacobus WE, Becker LC. The functional recovery of post-ischemic myocardium requires glycolysis during early reperfusion. J Mol Cell Cardiol. 1993;25:261-76.

16. Young HH, Shimizu T, Nishioka K, Nakanishi T, Jarmakani JM. Effect of hypoxia and reoxygenation on mitochondrial function in neonatal myocardium. Am J Physiol. 1983;245:H998-1006.

17. Lopaschuk GD, Spafford MA, Marsh DR. Glycolysis is predominant source of myocardial ATP production immediately after birth. Am J Physiol. 1991;261:H1698-705.

18. Medina JM. The role of lactates as energy substrate for brain during the early neonatal period. Biol Neonate. 1985;48:237-44.

19. Phelps RL, Metzger BE, Freinkel N. Carbohydrate metabolism in pregnancy. X VII. Diurnal profiles of plasma glucose, insulin, free fatty acids, triglycerides, cholesterol, and individual acids in the late normal pregnancy. Am J Obstet Gynecol. 1981;140:730-6.

20. Goodwin CW, Mela L, Deutsch C, Forster RE, Miller LD, Delivoria-
Papadopoulous M. Development and adaptation of heart mitochondria respiratory chain function in fetus and newborn. Adv Exp Med Biol. 1976;75:713-9.

21. Glatz JFC, Veerkamp JH. Postnatal development of palmitate oxidation and mitochondrial enzyme activities in rat cardiac and skeletal muscle. Biochim Biophys Acta. 1982;711:327-35.

22. Mueckler M. Family of glucose-transporter genes. Implications for glucose homeostasis and diabetes. Diabetes. 1990;39:6-11.

23. Sun DW, Nguyen N, DeGrado TR, Schwaiger M, Grosius FC. Ischemia induces translocation of the insulin-responsive glucose transporter Glut-4 to the plasma membrane of cardiac myocytes. Circulation. 1994;89:793-8.

24. Friehs I, Moran AM, Stamm C, Takeuchi K, Cao-Danh H, Rader CM, et al. Impaired glucose transporter activity in pressure-overload hypertrophy is an early indicator of progression to failure. Circulation. 1999;100:II-187-93.

25. Friehs I, Stamm C, Cao-Danh H, McGowan FX, del Nido PJ. Insulinlike growth factor-1 protects hypertrophied hearts from ischemic injury. Ann Thorac Surg. 2001;72:1650-6.

26. Bell GI, Kayano T, Buse JB, Burant CF, Takeda J, Lin D, et al. Molecular biology of mammalian glucose transportes. Diabetes Care. 1990;13:198-208.

27. Thorens B, Charron MJ, Lodish HF. Molecular physiology of glucose transporters. Diabetes Care. 1990;13:548-64.

28. Mueckler M. Facilitative glucose transporters. Eur J Biochem. 1994; 219:713-25

29. Stephens J, Pilch P. The metabolic regulation and vesicular transport of Glut-4, the major insulin-responsive glucose transporter. Endocr Rev. 1995;16:529-46.

30. Kahn BB. Facilitative glucose transporters: regulatory mechanisms and dysregulation in diabetes. J Clin Invest. 1992;89:1367-74.

31. Slot JW, Geuze HJ, Gigengack S, James DE, Lienard GE. Translocation of the glucose transporter Glut-4 in cardiac myocytes of the rat. Proc Natl Acad Sci USA. 1991;88:7815-9.

32. Kahn BB, Charron MJ, Lodish HF, Cushman SW, Flier JS. Differential regulation of two glucose transporters in adipose cells from diabetic and insulin-treated diabetic rats. J Clin Invest. 1989;84: 404-11.

33. Holman GD, Cushman SW. Subcellular localization and trafficking of the GLUT-4 glucose transporter isoform in insulin-responsive cells. Bioessays. 1994;16:753-9.

34. Santalucia T, Camps M, Castello A, Munoz P, Nuel A, Testar X, et al. Developmental regulation of Glut-1 (erythroid/Hep G2) and Glut-4 (muscle/fat) glucose transporter expression in rat heart, skeletal muscle and brown adipose tissue. Endocrinology. 1992;130:837-46.

35. Asano T, Shibasaki Y, Kasuga M, Kanazawa Y, Takaky F, Akanuma $\mathrm{Y}$, et al. Cloning of a rabbit brain glucose transporter cDNA and alteration of glucose transporter mRNA during tissue development. Biochem Biophys Res Commun. 1988;154:1204-11.

36. Sivitz W, DeSautel S, Walker PS, Pessin JE. Regulation of the glucose transporter in developing rat brain. Endocrinology. 1989; 124:1875-80.

37. Wang C. Insulin-stimulated glucose uptake in rat diaphragm during postnatal development: lack of correlation with the number of insulin receptors and of intracellular glucose transporters. Proc Natl Acad Sci USA. 1985;82:3621-8.

38. Castello A, Rodriguez-Manzaneque JC, Camps M, Perez-Castillo A, Testar X, Palacin M, et al. Perinatal hypothyroidism impairs the normal transition of Glut- 4 and Glut- 1 glucose transporters from fetal to neonatal levels in heart and brown adipose tissue. J Biol Chem. 1994;269:5905-12.

39. Chizzonite RA, Zak R. Regulation of myosin isoenzyme composition in fetal and neonatal rat ventricle by endogenous thyroid hormones. J Biol Chem. 1984;259:12628-32.

40. Casla A, Rovira A, Wells JA, Dohm GL. Increased glucose transport (Glut-4) protein expression in hyperthyroidism. Biochem Biophys Res Comm. 1990;171:182-8.

41. Jeremy RW, Korestsune Y, Marban E, Becker LC. Relation between glycolysis and calcium homeostasis in postischemic myocardium. Circ Res. 1992;70:1180-90. 
42. Lopaschuk GD, Spafford MA, Davies NJ, Wall SR. Glucose and palmitate oxidation in isolated working rat hearts reperfused after a period of transient global ischemia. Circ Res. 1990;66:546-53.

43. Kubler W, Spieckermann PG. Regulation of glycolysis in the ischemic and anoxic myocardium. J Mol Cell Cardiol. 1970;1:351-77.

44. Russell RR, Yin R, Caplan MJ, Hu X, Ren J, Shulman GI, et al.
Additive effects of hyperrinsulinemia and ischemia on myocardial GLUT-1 and GLUT-4 translocation in vivo. Circulation. 1998;98: 2180-6.

45. Egert S, Nguyen N, Schwaiger M. Myocardial glucose transporter GLUT-1: translocation induced by insulin and ischemia. J Mol Cell Cardiol. 1999;31:1337-44.

\section{Targeted}

The Journal of Thoracic and Cardiovascular Surgery gives you two tables of contents.

The condensed table of contents tells you at a glance what topics and authors are presented each month. The expanded table of contents gives you a brief abstract of each article. You select only those articles of most interest to you for further reading. 